\title{
SUELLEN SERAFINI
}

\section{Utilização da biópsia de mucosa e submucosa retal para o diagnóstico da Moléstia de Hirschsprung}

\author{
Dissertação apresentada à Faculdade de Medicina da \\ Universidade de São Paulo para obtenção do título de \\ Mestre em Ciências \\ Programa de Pediatria \\ Orientadora: Profa . Dra. Ana Cristina Aoun Tannuri
}

São Paulo 
Dados Internacionais de Catalogação na Publicação (CIP)

Preparada pela Biblioteca da

Faculdade de Medicina da Universidade de São Paulo

Creprodução autorizada pelo autor

Serafini, Suellen

Utilização da biópsia de mucosa e submucosa retal para o diagnóstico da Moléstia de Hirschsprung / Suellen Serafini. -- São Paulo, 2017.

Dissertação(mestrado)--Faculdade de Medicina da Universidade de São Paulo. Programa de Pediatria.

Orientadora: Ana Cristina Aoun Tannuri.

Descritores: 1.Doença de Hirschsprung 2.Reto/biópsia 3.Submucosa 4.Acetilcolinesterase 5.Hematoxilina-eosina 6.Calretinina

USP/FM/DBD-179/17 
Este trabalho foi desenvolvido no Laboratório de Cirurgia Pediátrica da FMUSP (LIM 30) e no Laboratório de Imunohistoquímica do Departamento de Patologia da FMUSP.

O projeto foi aprovado na Comissão de Ética e Pesquisa da Faculdade de Medicina da Universidade de São Paulo, em sessão de 13/08/2012, sob número 70633. 
Se você faz tudo sempre igual é seguro que não se perca, mas é possivel que nunca se ache.

Sérgio Vaz 
Aos meus pais, Luiz e Ione, por todo o carinho e dedicação. Aos meus irmãos, Kiko e Dani, pela camaradagem. À minha família do coração, tia Marilda, Mari e Vi, pela certeza de que sempre posso contar com vocês. 


\section{AGRADECIMENTOS}

À Profa. Dra. Ana Cristina Aoun Tannuri, por sua orientação durante este trabalho, pela sua participação no meu crescimento acadêmico e pela sua dedicação e energia na área de pesquisa que contagia a todos que estão a sua volta.

À Dra. Maria Mercês Santos, por ser orientadora, professora, amiga e "mãe". Sem os seus ensinamentos nada disso seria possível. Obrigada!

Ao Prof. Dr. Uenis Tannuri, um ser humano de caráter admirável, um cirurgião brilhante e um chefe que sempre incentiva os seus funcionários a enriquecer seus conhecimentos.

À equipe do LIM 30 - HC FMUSP Cecília, Patrícia e Josiane, por toda a ajuda nesse trabalho e pelo companheirismo. É muito bom ter amigas como vocês!

À Profa. Dra. Maria Claudia Nogueira Zerbini, pelo tempo dedicado a este trabalho, e pelos ensinamentos em Patologia. E as funcionárias do laboratório de Imunohistoquímica por sua ajuda.

Ao Dr. Ulysses Doria Filho, por seu auxilio durante a obtenção dos dados estatísticos.

Aos outros membros participantes da banca de Qualificação: Prof. Dr.

Evandro Sobroza Melo e Dra. Maria Esther Jurfest Rivero Ceccon e aos 
membros suplentes Dr. Celso Di Loreto e Prof. Dr. Clovis Artur Almeida da Silva. Agradeço pelas sugestões e pela gentileza.

A todos os técnicos do DAP, pela paciência em me ensinar todo o processo de parafinização, inclusão e corte de tecidos.

E ao meu segundo chefe Dr. Eugênio Raul Pimentel, por sua compreensão durante todo esse processo. 


\section{NORMATIZAÇÃO ADOTADA}

Esta dissertação está de acordo com as seguintes normas, em vigor no momento desta publicação:

Referências: adaptado de International Committee of Medical Journals Editors (Vancouver).

Universidade de São Paulo, Faculdade de Medicina. Serviço de Biblioteca e documentação. Guia de apresentação de dissertações, teses e monografias. Elaborado por Anneliese Carneiro da Cunha, Maria Julia de A. L. Freddi, Maria F. Crestana, Marinalva de Souza Aragão, Suely Campos Cardoso, Valéria Vilhena. 3a ed. São Paulo: Divisão de Biblioteca e Documentação; 2011.

Abreviaturas dos títulos dos periódicos de acordo com List of Journals Indexed in Index Medicus. 


\section{Sumário}

LISTA DE FIGURAS

LISTA DE GRÁFICOS

LISTA DE TABELAS

LISTA DE ABREVIATURAS E SIGLAS

RESUMO

\section{ABSTRACT}

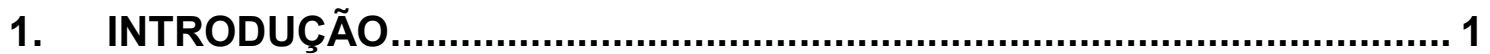

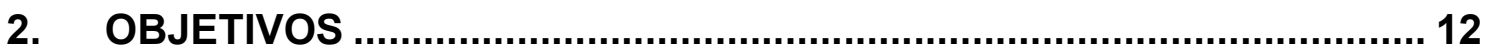

3. MATERIAL E MÉTODOS .............................................................. 14

3.1. Método de seleção dos casos .......................................... 15

3.2. Técnicas de preparo do tecido congelado.............................. 16

3.2.1. Método da pesquisa de atividade de acetilcolinesterase..... 17

3.3. Técnica de parafinização ................................................. 18

3.3.1. Método Hematoxilina-Eosina...................................... 19

3.3.2. Método Imunohistoquímico da Calretinina ...................... 20

3.4. Avaliação das lâminas..................................................... 21

3.5. Análise Estatística ......................................................... 23

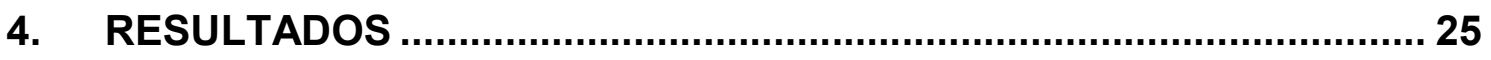

4.1. Comparação entre o método AChE com HE............................. 26

4.2. Comparação entre o método AChE com a Calretinina.................. 28

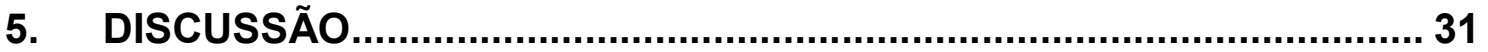

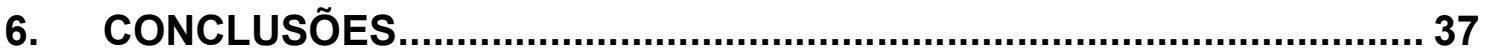

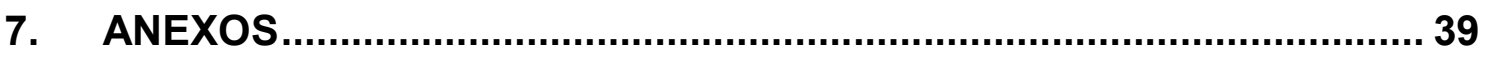

8. REFERÊNCIAS BIBLIOGRÁFICAS ............................................... 42 


\section{LISTA DE FIGURAS}

Figura 1 - Método de montagem da biópsia para o corte.

Figura 2 - Reagentes e panela Pascal utilizados no preparo da técnica imunohistoquímica.

21

Figura 3 - Imagens de neurônios fotografados na região da submucosa durante a análise do HE. Aumento de 40x.

Figura 4 - Imagens de lâminas com marcação pela calretinina. Fotos a, b e c mostrando neurônios marcados com aumento de 20x. Foto d mostrando as fibrilas finas na lâmina própria, 40x 23

Figura 5 - Imagem dos casos de HE onde outras estruturas presentes foram interpretadas como neurônios. a aumento de 10x, b e c 20x. 26 Figura 6 - Caso onde ocorreu uma marcação inespecífica na reação da calretinina, levando a um diagnóstico equivocado de não doente. Aumento de $20 x$. 


\section{LISTA DE GRÁFICOS}

Gráfico 1 - Comparação entre o diagnóstico realizado pela técnica do HE com os da AChE (padrão ouro). Negativo significa não doente e Positivo presença de $\mathrm{MH}$, para ambos os métodos. 27

Gráfico 2 - Localização da célula neural durante a leitura das lâminas de HE. Nível aproximado.

Gráfico 3 - Comparação entre o diagnóstico realizado pela técnica imunohistoquímica da Calretinina com os da AChE (padrão ouro). Negativo significa não doente e Positivo presença de $\mathrm{MH}$, para ambos os métodos. .... 30 


\section{LISTA DE TABELAS}

Tabela 1 - Comparação entre o diagnóstico realizado pela técnica do HE com os da AChE (padrão ouro). Negativo significa não doente e Positivo presença de $\mathrm{MH}$, para ambos os métodos.

Tabela 2 - Valores para validação do teste diagnóstico segundo a técnica da Hematoxilina \& eosina.

Tabela 3 - Comparação entre o diagnóstico realizado pela técnica imunohistoquímica da Calretinina com os da AChE (padrão ouro). Negativo significa não doente e Positivo presença de $\mathrm{MH}$, para ambos os métodos. .... 29 Tabela 4 - Valores para validação do teste diagnóstico segundo a técnica imunohistoquímica da calretinina. 30 


\section{LISTA DE ABREVIATURAS E SIGLAS}
AChE
Acetilcolinesterase
DAB Diaminobenzidina

HCFMUSP Hospital das Clínicas da Faculdade de Medicina da Universidade de São Paulo

HE Hematoxilina e Eosina

ICR Instituto da Criança

LIM Laboratório de Investigação Médica

MH Moléstia de Hirschsprung

SNE Sistema Nervoso Entérico

TBS Tris- buffered saline 


\section{RESUMO}

Serafini S. Utilização da biópsia de mucosa e submucosa retal para o diagnóstico da Moléstia de Hirschsprung [Dissertação]. São Paulo: Faculdade de Medicina, Universidade de São Paulo; 2017.

Introdução: A moléstia de Hirschsprung $(\mathrm{MH})$ se caracteriza pela ausência de neurônios intramurais em segmentos variáveis do intestino grosso, levando a suboclusão intestinal. $\mathrm{Na}$ forma mais frequente o reto-sigmoide está comprometido. A biopsia retal é o método histológico de escolha no diagnóstico da $\mathrm{MH}$. O método da hematoxilina e eosina $(\mathrm{HE})$ é classicamente utilizado na prática histopatológica. Nessa técnica, um fragmento de parede total do reto é processado através de parafinização, para posteriormente ser seccionado e corado por HE. Esta coloração evidencia células neurais em intestinos normais e troncos nervosos hipertrofiados nos casos de $\mathrm{MH}$. É uma técnica muito simples, ainda hoje muito utilizada no diagnóstico da doença, necessitando de fragmentos grandes de reto para um maior acerto no diagnóstico. Este detalhe torna o diagnóstico do recém-nascido mais difícil. Outro método de coloração utilizado no diagnóstico da MH é o método histoquímico de pesquisa de atividade de Acetilcolinesterase (AChE). Nesta técnica é necessário apenas um pequeno fragmento de mucosa e submucosa que será congelado e depois processado. A pesquisa de AChE, nos casos de MH mostrará a presença desta enzima em quantidade aumentada, corando troncos e ou fibrilas de cor acastanhado. Este método já vem sendo utilizado pelo Instituto da Criança - HCFMUSP há mais de 30 anos e possui um acerto diagnóstico superior a $90 \%$. Porém, por ser uma técnica mais elaborada, pouquíssimos centros no Brasil a utilizam no diagnóstico da $\mathrm{MH}$. Um outro método mais recente, e que também pode ser realizado em fragmentos menores, é a marcação imunohistoquímica da calretinina, que permite a visualização dos neurônios do plexo submucoso e das fibrilas finas na região da lâmina própria em não doentes. Esta técnica também apresenta maior complexidade e, portanto, não é utilizada. A possibilidade de realizar 0 diagnóstico da $\mathrm{MH}$ através da coloração $\mathrm{HE}$ em fragmentos menores poderia ser uma alternativa para os serviços que não dispõe de técnicas mais especificas. Objetivos: Avaliar a concordância dos resultados obtidos pelo método de coloração HE e da calretinina com a pesquisa de atividade de AChE em fragmentos de mucosa e submucosa no diagnóstico da Moléstia de Hirschsprung. Métodos: Para este trabalho foram selecionados 50 casos arquivados em nosso laboratório. O material encontrava-se emblocado em parafina. Foram feitos 60 níveis de cada fragmento para o HE e mais 3 níveis para a calretinina. Essas lâminas foram analisadas em microscópio, fotografadas e classificadas como positivas para MH quando não foram encontradas células neurais e houve a presença de troncos nervosos, e em negativas nos casos de visualização dos neurônios. Foi realizado estudo cego por dois pesquisadores. Os resultados da leitura das lâminas foram comparados com o da AChE. Resultados: Dos 50 casos avaliados pela técnica do HE, apenas 5 discordaram do diagnóstico realizado pela AChE, com um valor de Kappa de 0,800 e acurácia $90 \%$. Na comparação entre a calretinina e a AChE 8 casos discordaram, com um valor de Kappa de 0,676 e acurácia de 84\%. Conclusões: A concordância obtida 
entre os métodos da AChE e HE foi satisfatória. Tornando possível a utilização do método do HE em 60 níveis de fragmento de mucosa e submucosa como alternativa para o diagnóstico da $\mathrm{MH}$. A técnica imunohistoquímica da Calretinina não apresentou a concordância esperada com a pesquisa de atividade de AChE em nosso estudo.

Descritores: doença de Hirschsprung; reto/biópsia; submucosa; acetilcolinesterase; hematoxilina-eosina; calretinina. 


\begin{abstract}
Serafini S. Utilization of mucosal and submucosal rectal biopsy for the diagnosis of Hirschsprung's disease [Dissertation]. São Paulo: "Faculdade de Medicina, Universidade de São Paulo"; 2017.

Introduction: Hirschsprung disease (HD) is characterized by the absence of intramural neurons in variable segments of the large intestine, leading to intestinal subocclusion. In the most frequent form the rectum-sigmoid is compromised. Rectal biopsy is the histological method of choice in the diagnosis of HD. The hematoxylin and eosin ( $\mathrm{HE}$ ) method is classically used in histopathological practice. In this technique, a full-thickness rectum wall fragment is processed through paraffinization, to be later sectioned and stained by HE. This staining shows neural cells in normal intestines and hypertrophied nerve trunks in cases of HD. It is a very simple technique, still used today in the diagnosis of the disease, requiring large fragments of the rectum for a better diagnosis. This detail makes the diagnosis of the newborn more difficult. The staining histochemical methods more used are the research of acetylcholinesterase activity (AChE) and staining of calretinin. However, these techniques are not available in all centers and the possibility of diagnosing HD through HE staining in smaller fragments could be valuable alternative for services that do not have more specific techniques. Objectives: To evaluate the concordance of the results obtained by the HE staining and the calretinin method with the investigation of AChE activity in fragments of mucosa and submucosa in the diagnosis of Hirschsprung's disease. Methods: For this study, 50 cases from our laboratory were selected. The material was embedded in paraffin. Sixty levels of each fragment were made for $\mathrm{HE}$ and other 3 levels for calretinin. These slides were analyzed under microscope, photographed and classified as positive for HD when no nerve cells were found and there were nerve trunks present, and in negative in cases of visualization of the neurons. A blind study was carried out by two researchers. The results of reading the slides were compared with that of AChE. Results: Of the 50 cases evaluated by the HE technique, only 5 disagreed with the diagnosis performed by AChE, with a Kappa value of 0.800 and accuracy of $90 \%$. In the comparison between calretinin and AChE, 8 cases disagreed, with a Kappa value of 0.676 and an accuracy of $84 \%$. Conclusions: The concordance of results from AChE and HE methods was satisfactory, allowing the possibility of the use of the $\mathrm{HE}$ method in fragments of mucosa and submucosa as valid alternative for the diagnosis of HD. The immunohistochemical technique of Calretinin did not show a good agreement with the AChE activity in our study.
\end{abstract}

Descriptors: Hirschsprung's disease; rectum/biopsy; submucosa; acetylcholinesterase; hematoxylin-eosin; calretinin. 
1. INTRODUÇÃO 
A Moléstia de Hirschsprung $(\mathrm{MH})$, também conhecida como megacólon congênito caracteriza-se pela ausência de neurônios intramurais em segmentos variáveis do intestino grosso resultando em não propulsão intestinal no segmento afetado ${ }^{1,2}$.

Esta doença foi descrita em 1886 por Harald Hischsprung, através do estudo de duas crianças com constipação e distensão abdominal. Na autopsia foi observada a relação entre os sintomas graves de constipação e suboclusão intestinal associados com a hipertrofia e dilatação dos colos ${ }^{3,4}$.

Este trabalho estabeleceu os padrões clínicos da doença, porém a fisiopatologia manteve-se desconhecida. Tittel, em 1901, foi o primeiro a descrever uma diminuição dos plexos intramurais em casos analisados. Entretanto, somente muito tempo depois, em 1948, estudos de Whitehouse e Kernohan definiram a etiopatogenia da $\mathrm{MH}$, caracterizada pela ausência de gânglios mioentéricos e a hipertrofia de troncos nervosos 5,6 .

A MH possui uma incidência de 1:5000 nascidos vivos, sendo considerada a causa mais comum de obstrução intestinal baixa em recémnascidos, com uma prevalência de gênero de 4:1 para o sexo masculino. Um estudo realizado em 1997 demonstrou que havia diferença na distribuição da doença entre raças, com incidência de 1,5:10.000 em brancos, 2,1:10.000 em negros, 1:10.000 em hispânicos e 2,8:10.000 em asiáticos $3,7,8$. 
Existem várias hipóteses que têm sido examinadas para explicar a causa da $\mathrm{MH}$. Uma hipótese seria decorrente da interrupção do deslocamento dos neuroblastos durante o processo de formação do sistema nervoso entérico, e outra a degeneração dos neuroblastos durante o período de diferenciação em células ganglionares. Entre estas, a primeira é a mais aceita ${ }^{9,10}$.

A compreensão do processo de desenvolvimento do sistema nervoso entérico é útil na interpretação dos exames histopatológicos utilizados no diagnóstico da doença. É também de valia no entendimento de como a MH pode afetar extensões variáveis do intestino.

O sistema nervoso entérico (SNE) consiste em uma rede de neurônios dispersos ou reunidos em pequenos gânglios nos plexos submucoso e mioentérico. Estes plexos possuem uma extensa variedade de tipos neuronais, com grande quantidade de neurotransmissores e receptores, que controlam a motilidade intestinal e vascular ${ }^{11}$.

Estudos mostram que o desenvolvimento do SNE se inicia a partir da $5^{\mathrm{a}}$ semana de gestação. Neste período, os neuroblastos, células provenientes dos segmentos vagal e sacral da crista neural, começam a se deslocar através do mesênquima do tubo digestivo no sentido crânio-caudal ${ }^{12,13,14,15}$.

Este processo se dará gradativamente, de tal forma que por volta da $8^{a}$ semana de gestação ainda não são encontrados neuroblastos na parte distal do colo e do reto, o que só irá ocorrer na $12^{\mathrm{a}}$ semana de gestação ${ }^{5,16}$. Estudos de Okamoto e Ueda, em 1967, em embriões e fetos humanos comprovaram estes resultados ${ }^{13}$. 
Um outro aspecto de interesse diz respeito à maturação dos neurônios que irá ocorrer entre a $10^{\mathrm{a}}$ e a $18^{\mathrm{a}}$ semana gestacional. Durante esse período, é possível encontrar no tubo digestivo, neurônios maduros, diferenciados, e neurônios imaturos ${ }^{6,18,19,20}$.

Essas células, responsáveis pela formação dos plexos neurais intestinais, migram internamente na parede intestinal em direção à mucosa, formando primeiro o plexo mioentérico de Auerbach e em seguida os plexos submucosos de Meissner (submucoso superficial) e Henley (submucoso profundo). Ambos os plexos, mioentérico e submucosos, se interconectam através de feixes nervosos ${ }^{15,19}$.

Do ponto de vista da distribuição dos plexos nervosos, o plexo mioentérico apresenta neurônios organizados em gânglios concentrados entre as camadas musculares. Já o plexo submucoso se organiza da mesma forma, porém com uma distribuição mais difusa ${ }^{16,20}$.

Os neurônios dos plexos nervosos entéricos (submucosos e mioentérico), em conjunto com a ação dos nervos autônomos extrínsecos irão conferir a motilidade intestinal adequada ${ }^{11,17}$.

$\mathrm{Na}$ inervação normal do intestino, as fibras parassimpáticas préganglionares dos nervos vago e pélvico realizam sinapse com as células ganglionares intramurais e emitem fibras que irão inervar a parede intestinal. Já as fibras simpáticas (pós-ganglionares) adentram o intestino sem inervar diretamente a musculatura intestinal ${ }^{11,21}$. 
As sinapses colinérgicas que ocorrem entre os neurônios do SNE são realizadas através da ação do mediador químico acetilcolina (parassimpático). A acetilcolina é quebrada pela atividade enzimática das colinesterases ${ }^{22,23}$.

Na Moléstia de Hirschsprung, por razões ainda não esclarecidas, ocorre a interrupção do processo migratório dos neuroblastos, determinando a ausência de células neurais no segmento de intestino acometido ${ }^{14}$.

Vários estudos relacionados à genética têm sido realizados com o intuito de explicar qual é a causa dessa ausência de neurônios. Sabe-se que há um risco aumentado para $\mathrm{MH}$ entre irmãos de indivíduos afetados. Esse risco pode variar de acordo com o sexo e com tamanho de segmento afetado pela doença. Mas o risco de recorrência global entre irmãos é de aproximadamente $4 \%{ }^{24,25}$.

Os fatores genéticos possuem interações complexas que influenciam na penetrância e no grau de severidade da doença². Atualmente, mutações em 11 genes já foram descritas relacionadas à aganglionose. Dentre estes genes o gene RET é o que apresenta as mutações mais comuns, estando presente em 7 a $35 \%$ dos $\operatorname{casos}^{24,25}$.

A MH também pode estar associada à algumas anomalias congênitas como a síndrome de Waardenburg e com a trissomia do cromossomo 21. Pacientes com síndrome de Down possuem um risco 100 vezes maior de apresentar a doença ${ }^{25}$. Porém todas as alterações genéticas descritas acima correspondem apenas a minoria dos casos, pois $80 \%$ ainda permanecem sem explicação ${ }^{26}$. 
A ausência de células neurais nos plexos nervosos intestinais é a característica anatomopatológica clássica da $\mathrm{MH}$, que se acompanha de hipertrofia de troncos nervosos. Em consequência deste aspecto haverá contração e hipertrofia das fibras musculares acima da região afetada ${ }^{27}$.

A ausência de peristaltismo na zona aganglionar dificulta o trânsito intestinal determinando a dilatação do colo normal, ganglionar, localizado acima da zona doente. Esta alteração de motilidade é responsável pelos sintomas clínicos de suboclusão intestinal identificado em pacientes com $\mathrm{MH}^{28}$.

Os pacientes acometidos pela $\mathrm{MH}$, classicamente, apresentam no período neonatal, distensão abdominal, dificuldade na eliminação de mecônio, e vômitos. Ao toque retal ocorre a eliminação explosiva de gazes e fezes. Em alguns casos os sintomas de obstipação intestinal podem surgir tardiamente, se agravando de forma progressiva, à medida que os alimentos sólidos são introduzidos 27,29 .

Quanto mais precoce a interrupção do movimento migratório dos neuroblastos, maior será o segmento afetado, sendo que o reto sempre apresentará ausência de neurônios ${ }^{6,30}$

A variedade clínica da $\mathrm{MH}$ está relacionada com a extensão do segmento comprometido. Na forma clássica da doença o reto e o sigmóide encontram-se doentes. Esta é a forma mais comum e ocorre em $80 \%$ dos $\operatorname{casos}^{27,28}$. Já na aganglionose cólica total haverá o comprometimento de todo colo. 
Existem alguns métodos utilizados no diagnóstico da $\mathrm{MH}$. O enema opaco é um exame de imagem frequentemente utilizado. Nos casos de $\mathrm{MH}$ poderá ser observada a zona de transição entre a região normal dilatada e a região de menor calibre, que corresponde a região sem neurônios ${ }^{9,27}$.

Um outro exame possível de ser utilizado é a manometria anorretal, que irá averiguar a existência do reflexo de abertura do esfíncter interno do paciente. Quando este reflexo está presente afasta-se a possibilidade da doença, por outro lado, quando ausente pode ser sugestivo de $\mathrm{MH}^{9,27}$.

Entretanto, o método diagnóstico de certeza para a $\mathrm{MH}$ é realizado através do estudo anatomopatológico de material coletado da parede intestinal por biópsia ${ }^{27}$.

$\mathrm{Na}$ investigação dos pacientes com suspeita de $\mathrm{MH}$, o estudo histopatológico pode ser realizado pela análise de um fragmento de reto, tendo em vista que nas diferentes variedades clinicas da doença o reto deverá estar afetado. Esse material deverá ser obtido a $1,5 \mathrm{~cm}$ acima da linha pectínea $^{30,31,32,33}$.

O fragmento obtido através da biópsia deverá ser processado por parafinização ou congelamento e corado, para a análise histopatológica.

O método clássico utilizado para o diagnóstico de MH é o da biópsia de parede total do reto tratada por coloração Hematoxilina \& Eosina $(\mathrm{HE})$ com uma acurácia de $98 \%{ }^{34,35,36}$.

O método HE é uma das colorações frequentemente utilizadas em estudos anatomopatológicos, e o seu preparo é de grande facilidade. A 
hematoxilina é um corante básico que irá fazer ligação com componentes ácidos. Através de um processo de oxidação, haverá a conversão da hematoxilina em hemateína, composto de cor púrpura que irá corar os núcleos celulares. Já a eosina possui uma cor laranja-rosada e é utilizada na contra-coloração da hematoxilina, conferindo um tom rosado ao citoplasma ${ }^{37}$.

Em um bom preparo histológico de fragmento de parede intestinal normal tratado por esta coloração, é possível evidenciar os gânglios e neurônios nos plexos da parede intestinal. A presença de células neuronais afasta a possiblidade de megacolon congênito. Caracteristicamente na $\mathrm{MH}$, as células ganglionares não serão observadas nos plexos nervosos, existindo a hipertrofia de troncos. ${ }^{27,34,38}$.

Um outro método utilizado para diagnosticar a doença é o método histoquímico de pesquisa de atividade da acetilcolinesterase. Este método foi descrito no ano de 1972, por Meier-Ruge. Observou-se que nos fragmentos de intestino doente havia um aumento de atividade da enzima acetilcolinesterase (AChE). Supõe-se que as células ganglionares funcionem como um sensor de crescimento, e que na falta delas as fibras nervosas, que são impregnadas de AChE, sofram hipertrofia e hiperplasia, espalhando-se em direção à mucosa. Desta forma, nos pacientes doentes com MH observa-se uma grande quantidade de fibras colinérgicas na mucosa e submucosa em comparação com um intestino normal $^{39}$. Estudos demonstraram que a coloração histoquímica de fragmentos através da pesquisa de AChE é um método eficiente no diagnóstico da $\mathrm{MH}^{40,41}$. Essa técnica vem sendo utilizada no laboratório da FMUSP - LIM30 há mais de 30 anos, com acerto superior a 90\%, sendo, portanto, um método especifico de 
alta sensibilidade, motivo pelo qual foi considerado padrão ouro pelo nosso serviço $0^{1,41,42}$.

Diferente do tradicionalmente utilizado no diagnóstico da $\mathrm{MH}$, o método de AChE necessita apenas de um pequeno fragmento de mucosa e submucosa obtido por biopsia retal ${ }^{24}$.

O fragmento é processado pela técnica de Karnovsky e Roots ${ }^{43}$, que é um método de coloração direta, havendo, após diversas reações, a formação de um precipitado acastanhado nas estruturas que apresentam atividade enzimática, troncos e fibrilas. Estas estruturas são de fácil identificação em microscópio óptico.

Outro método anatomopatológico que pode ser usado no diagnóstico de megacolon congênito são as técnicas de imunohistoquímica específicas para a identificação das estruturas do sistema nervoso entérico.

A técnica imunohistoquímica tem como princípio a utilização de marcadores para a visualização de proteínas especificas em determinados tecidos ou células. A reação é realizada em várias etapas. Em um primeiro momento, um anticorpo primário irá realizar uma ligação com o antígeno, em seguida um anticorpo secundário ligado covalentemente a um agente colorido fará ligação com anticorpo primário. As regiões onde houver a presença do antígeno irão adquirir uma coloração marrom, que pode ser visualizada em microscópio óptico 31. 
Entre os marcadores de imunohistoquímica que podem ser utilizados no estudo do sistema nervoso entérico destaca-se a calretinina que possui uma alta sensibilidade, também superior a $90 \% 44,45,46$.

A calretinina é uma proteína de ligação de cálcio, utilizada como marcador imunohistoquímico que irá sinalizar, sobretudo, as células ganglionares presentes nos plexos nervosos da parede intestinal, bem como as fibras nervosas finas na região da muscularis mucosae e lâmina própria no intestino normal. Em casos de $\mathrm{MH}$, esse marcador não irá marcar as células neurais, portanto não haverá atividade $35,44,49,51$.

Todos os métodos diagnósticos citados possuem vantagens e desvantagens. O exame de pesquisa por AChE apresenta grande vantagem não só pela sua sensibilidade no diagnóstico da doença, mas sobretudo porque é possível fazer o diagnóstico anatomopatológico com apenas a utilização de um pequeno fragmento de mucosa e submucosa com aproximadamente $3 \mathrm{~mm}$ de diâmetro por $2 \mathrm{~mm}$ de espessura. Desta forma, não haverá a necessidade de um fragmento de parede total do reto que é de mais difícil obtenção, especialmente em recém-nascidos ${ }^{32}$. Entretanto, o método da $A C h E$ não é tão acessível na prática clínica, por utilizar uma metodologia mais complexa do que a técnica de parafinização com coloração por HE. Além disso, o material de biópsia precisa ser preparado rapidamente para que não ocorra a autólise do fragmento ${ }^{52,53}$.

Por outro lado, os marcadores imunohistoquímicos, apesar de muito úteis, são também de maior complexidade na sua execução e de custo mais elevado. 
Entre os métodos descritos o de mais fácil execução, mais barato e o mais largamente utilizado pelos serviços é, sem dúvida, o de HE. Porém, apesar da facilidade técnica na execução deste método na investigação diagnóstica da $\mathrm{MH}$, usualmente é realizada a coleta de biópsia de parede total do reto. $\mathrm{Na}$ criança, nem sempre, este procedimento é de fácil obtenção.

A técnica de HE pode também ser realizada em biópsia de mucosa e submucosa da parede retal. Nestes casos, poderá haver dificuldade na análise dos fragmentos, pois a visualização das células ganglionares na submucosa é, sabidamente, mais difícil. Esta particularidade deve-se a menor quantidade dessas células nessa região, o que poderia causar uma interpretação errônea no diagnóstico, ou seja diagnóstico de falso positivo para $\mathrm{MH}$.

Estudos mostram que um meio de contornar esta questão seria a análise de um maior número de cortes de uma mesma amostra, de modo que aumente a probabilidade de identificação das células neuronais ${ }^{16,19,42}$.

Considerando o exposto, formulamos a hipótese de que seria possível o diagnóstico da $\mathrm{MH}$, em fragmentos de mucosa e submucosa tratados pelo método de coloração $\mathrm{HE}$, desde que seja analisado um maior número de secções destes fragmentos.

A utilização desta metodologia poderá contribuir no diagnóstico da $\mathrm{MH}$, sendo de grande valia, sobretudo, nos serviços brasileiros que não dispõe de equipamentos e equipe técnica treinada para a realização de métodos mais complexos e de maior custo como o AChE e a calretinina. 
2. OBJETIVOS 
A) Avaliar a concordância dos resultados obtidos pelo método de coloração HE com a pesquisa de atividade de AChE em fragmentos de mucosa e submucosa no diagnóstico da Moléstia de Hirschsprung.

B) Avaliar a concordância dos resultados obtidos pelo método imunohistoquímico da calretinina com a pesquisa de atividade de $\mathrm{AChE}$ em fragmentos de mucosa e submucosa no diagnóstico da Moléstia de Hirschsprung. 
3. MATERIAL E MÉTODOS 
Rotineiramente são processadas no Laboratório de Investigação Médica em Cirurgia Pediátrica (LIM30 - HCFMUSP) biópsias retais, provenientes de crianças atendidas no Instituto da Criança para o diagnóstico da Moléstia de Hirschsprung. Tendo em vista este objetivo, no ICR, são colhidas de cada criança com suspeita de $\mathrm{MH}$ dois pequenos fragmentos de reto, compreendendo mucosa e submucosa, ambos medindo aproximadamente três milímetros. Um dos fragmentos é congelado para a realização do método $A C h E$, e o outro fixado em solução de formol (10\%) e emblocado em parafina. Este material emblocado em parafina permanece arquivado em nosso laboratório para eventual necessidade de complementação no diagnóstico.

\subsection{Método de seleção dos casos}

Entre os anos de 2010 a 2015 foram realizadas em nosso serviço 98 biópsias destinadas ao diagnóstico de $\mathrm{MH}$. Deste total, 25 biópsias foram excluídas deste estudo, por não atenderem aos critérios de seleção.

Casos excluídos:

- Blocos que haviam sido utilizados previamente em estudos complementares: 8 casos;

- Material inadequado: 5 casos de epitélio estratificado e 12 casos de biópsia de colostomia. 
Restaram, portanto, 73 amostras adequadas para serem utilizadas neste estudo.

Os 73 blocos remanescentes foram cortados com o auxílio de um micrótomo eletrônico (Leica RM2255, German). Foram seccionados 60 níveis de $3 \mu$ por caso, para serem processados pela hematoxilina-eosina e mais 3 níveis para a realização de imunohistoquímica.

Durante a etapa dos cortes histológicos, alguns blocos não apresentaram material suficiente para atingir o número de 63 níveis requeridos. Esses 23 blocos também foram excluídos do trabalho. Restando assim 50 casos a serem analisados.

\subsection{Técnicas de preparo do tecido congelado}

O material, logo após a coleta, é apoiado em um bloco de fígado de rato para facilitar o posicionamento para o corte, com a mucosa voltada para o lado externo e a submucosa em contato com o fígado. Depois foi mergulhado em hexano e congelado em nitrogênio líquido em seguida.

Após a criogenização a peça é fixada em um disco metálico com o auxílio de meio específico de inclusão (Killik - EasyPath, Brasil) e cortada em criostato (IEC CTF Microtome-Cryostat - Damon, USA) mantido a $12^{\circ} \mathrm{C}$ negativos. Obteve-se, em média, 18 níveis de cortes histológicos de $10 \mu$ de espessura. Os cortes foram captados em lamínulas com a ajuda de um pincel. 


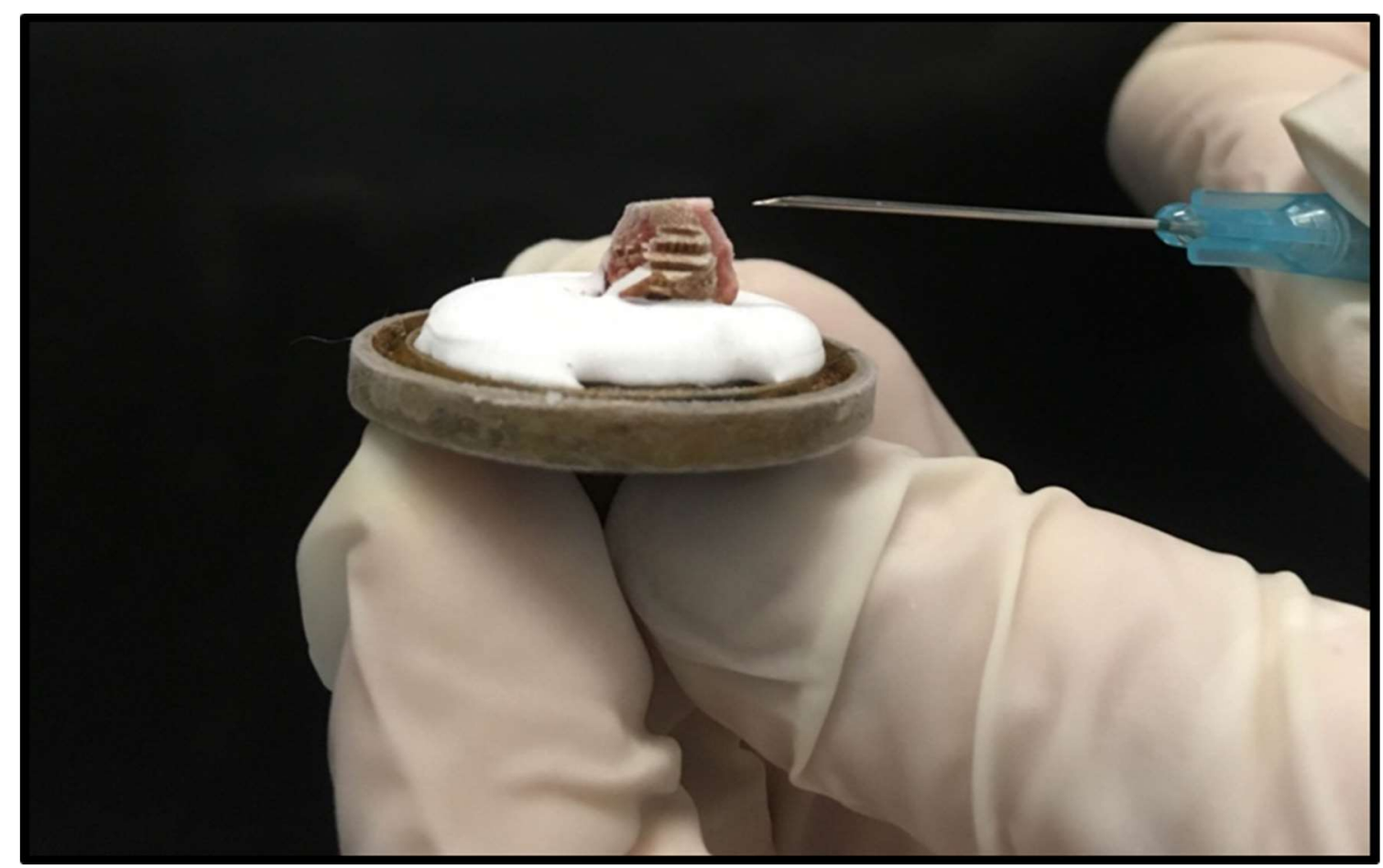

Figura 1 - Método de montagem da biópsia para o corte.

\subsubsection{Método da pesquisa de atividade de acetilcolinesterase}

Os fragmentos obtidos através da técnica de congelação foram processados pelo método histoquímico de Karnovsky e Roots ${ }^{43}$, com a modificação de Hanker et $\mathrm{al}^{54}$, que consiste na pesquisa de atividade de acetilcolinesterase.

Neste método, a acetilcolinesterase reduz o iodeto de acetilcolina em tiocolina livre que, por sua vez, reage com o ferricianeto de potássio transformando-o em ferrocianeto, o ferrocianeto reage com o sulfato de cobre, também presente na solução, formando sais de cobre que se depositam nos troncos nervosos localizados na região da submucosa e nas fibrilas que se encontram na mucosa e submucosa. Hanker e cols ${ }^{54}$ adicionaram tetraóxido de ósmio à reação, o que proporciona uma melhor visibilidade das fibras colinérgicas. 
$\mathrm{O}$ material foi incubado por 90 minutos em estufa à $37^{\circ} \mathrm{C}$. $\mathrm{O}$ meio de incubação consiste em:

- $5 \mathrm{mg}$ de iodeto de acetilcolina (Sigma Audrich - Germany)

- 6,5 ml de tampão acetato de sódio;

- $0,5 \mathrm{ml}$ de citrato de sódio $(0,1 \mathrm{M})$;

- $1 \mathrm{ml}$ de sulfato de cobre $(30 \mathrm{mM})$;

- $1 \mathrm{ml}$ de água destilada;

- $0,2 \mathrm{ml}$ de Iso-OMPA (4mM);

- $1 \mathrm{ml}$ de ferricianeto de potássio $(5 \mathrm{mM})$;

Após essa etapa, as lâminas foram lavadas em água destilada, contracoradas pela Hematoxilina de Carrazzi por 5 minutos, processadas pela etapa de desidratação e clareamento: álcool $70 \%$, álcool $80 \%$, álcool $90 \%$, álcool absoluto e xilol e em seguidas montadas com o auxílio de resina sintética (Entellan - Merck,German).

\subsection{Técnica de parafinização}

O material que foi fixado em formalina tamponada (10\%) permaneceu na solução de formol por um período de 24 horas. Após a fixação o tecido foi desidratado e diafanizado em um processador automático de tecidos (Lupe PT05, Brasil) conforme protocolo abaixo:

- Passagem por seis cubas de álcool absoluto, permanecendo 1 hora em cada cuba; 
- Passagem por três cubas de xilol, permanecendo 1 hora em cada cuba;

- Passagem por duas cubas de parafina a $60^{\circ} \mathrm{C}$, permanecendo 1 hora em cada cuba;

Posteriormente os fragmentos foram incluídos em blocos de parafina e armazenados em nossos arquivos.

\subsubsection{Método Hematoxilina-Eosina}

As lâminas contendo os 60 cortes seriados destinados ao HE foram desparafinizadas em estufa a $60^{\circ} \mathrm{C}$ por 30 minutos, com um banho de xilol quente e dois banhos de xilol à temperatura ambiente. A técnica de coloração Hematoxilina-eosina consiste em:

- 2 passagens em álcool absoluto;

- Lavagem em água corrente;

- 5 minutos imersas em Hematoxilina de Harris;

- Lavagem em água corrente;

- 3 minutos imersas em Eosina;

- 9 passagens em álcool absoluto;

- 3 passagens em xilol.

Após a coloração as lâminas foram montadas com auxílio de resina sintética (Entellan - Merck,German). 


\subsubsection{Método Imunohistoquímico da Calretinina}

Os níveis seccionados para a reação de imunohistoquímica foram colocados em lâminas silanizadas. Essas lâminas permaneceram 24 horas em estufa a $60^{\circ} \mathrm{C}$ para a desparafinização.

A calretinina é utilizada no diagnóstico de $\mathrm{MH}$ por marcar os neurônios presentes na submucosa e as fibrilas finas presentes na lâmina própria em caso de ausência da doença. Nos casos de MH positiva não há reação do marcador no fragmento estudado. As lâminas passaram pelo processo de desparafinização descrito acima, e em seguida foram realizadas as seguintes etapas:

- Recuperação antigênica - as lâminas foram mergulhadas em um tampão de citrato $\mathrm{pH}$ 6,0 e colocadas em panela pascal à temperatura de $125^{\circ} \mathrm{C}$, e pressão a 18 psi, por 30 segundos;

- Lavagem em água deionizada;

- Bloqueio da peroxidase endógena por 20 minutos em temperatura ambiente;

- Lavagem em água deionizada e banho de 5 minutos em tampão de lavagem TBST;

- Aplicação do anticorpo Rabbit Anti-Human Calretinin Monoclonal Antibody - Clone SP13 (Spring, USA) com diluição de 1:400;

- Após a aplicação do anticorpo as lâminas foram mantidas refrigeradas em câmara úmida "over-night";

- Aplicação do polímero de visualização - as lâminas foram retiradas do refrigerador para voltarem à temperatura ambiente e lavadas com 
tampão TBST o polímero N-Histofine (DBS, USA) foi aplicado e o material permaneceu incubado por 30 minutos em câmara úmida;

- Aplicação do substrato cromógeno Diaminobenzidina, DAB (DBS, USA) incubar por 10 minutos;

- Lavagem em água corrente;

- Contra - coloração com Hematoxilina de Harris.

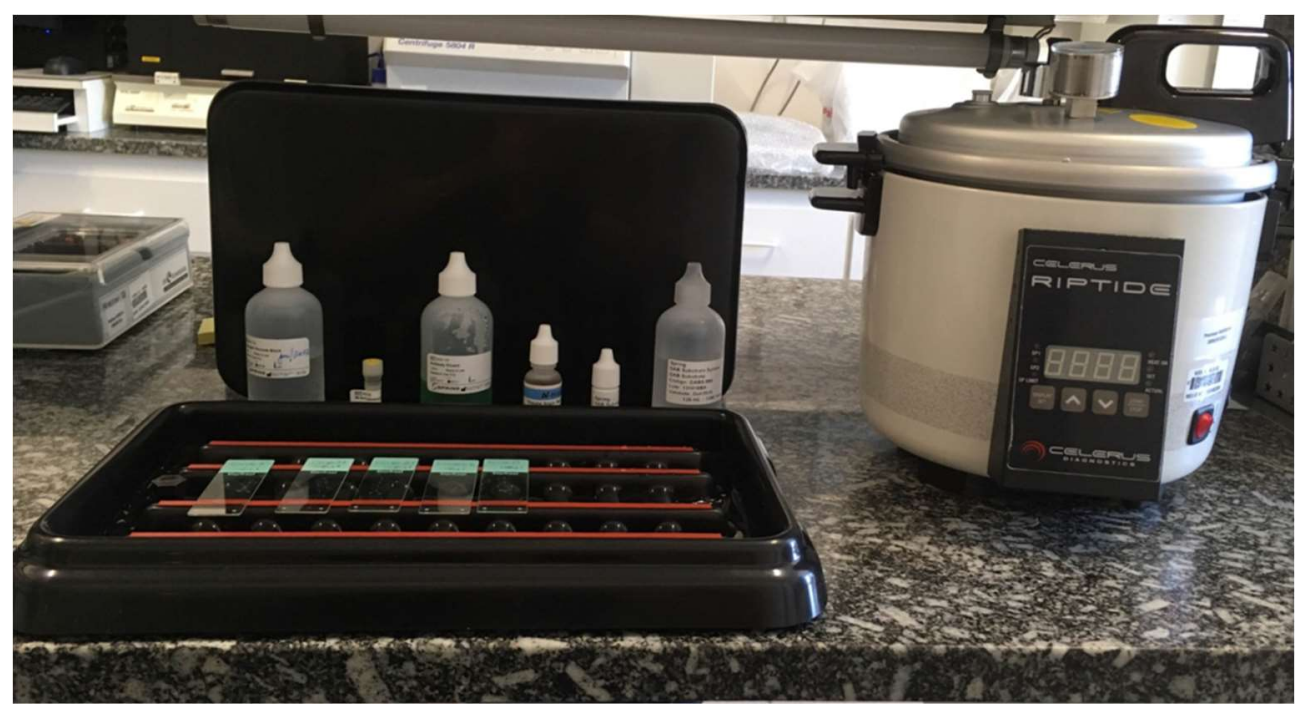

Figura 2 - Reagentes e panela Pascal utilizados no preparo da técnica imunohistoquímica.

\subsection{Avaliação das lâminas}

As lâminas preparadas pela técnica de HE e de imunohistoquímica foram analisadas por dois pesquisadores com o auxílio de microscópio ótico Nikon Eclipse 50i.

Para que não houvesse interferência no processo de leitura das lâminas, foi utilizado o método cego, onde ambos os pesquisadores desconheciam o diagnóstico anterior dos casos. Para este fim, uma terceira pessoa ficou responsável por numerar cada caso da seguinte forma:

- HE: numeração de H1 a H50 
- Calretinina: C1 a C50

As secções de tecido onde eram encontrados neurônios ou troncos nervosos foram documentadas através de fotografias com o auxílio de um programa de captação de imagens (Nis-Element Basic Research - Nikon,USA).

Para o diagnóstico por HE, todos os 60 cortes eram investigados a procura de células neuronais. Quando estas eram encontradas, era capturada uma imagem do achado e o diagnóstico era dado como não doente. Se dentre os 60 niveis não fosse visualizado nenhum neurônio, o caso era diagnosticado como $\mathrm{MH}$.

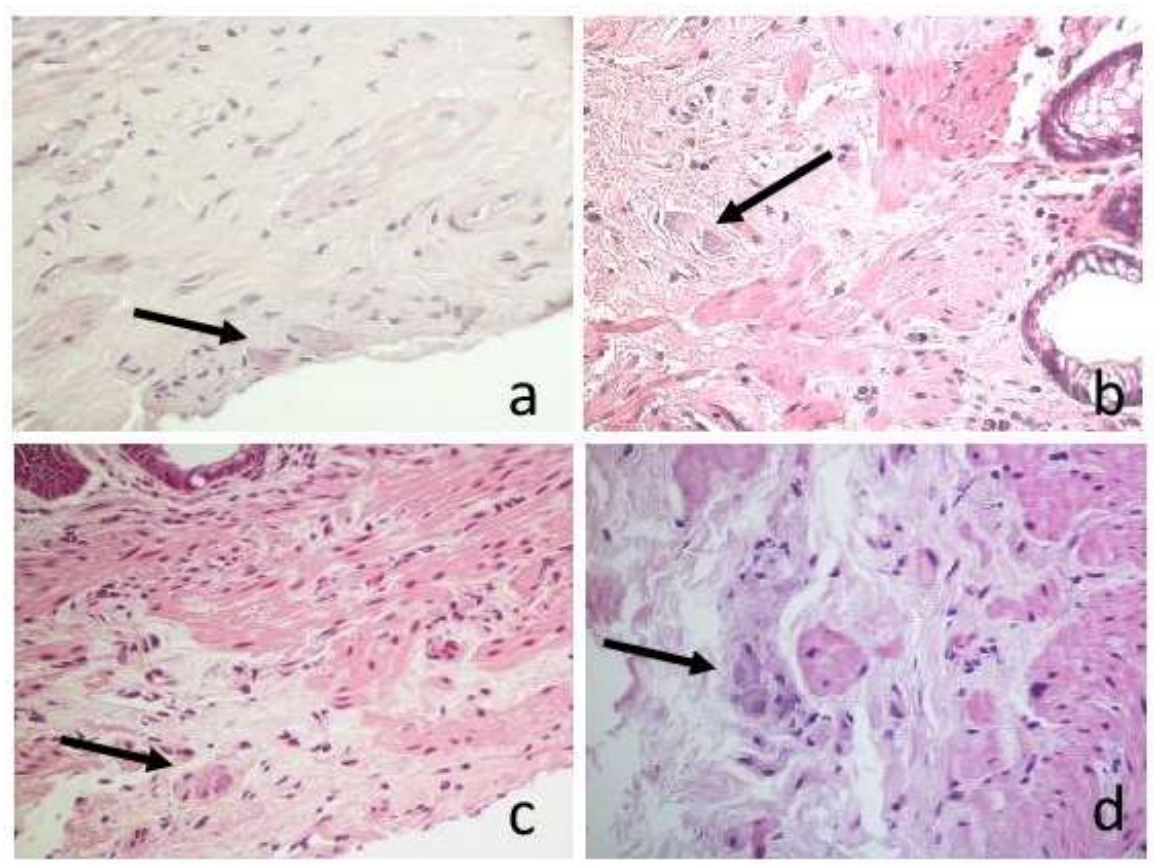

Figura 3 - Imagens de neurônios fotografados na região da submucosa durante a análise do HE. Aumento de 40x.

Já para a calretinina, se houvesse a marcação de células ganglionares na submucosa ou das fibrilas finas na região da lâmina própria, o caso era 
diagnosticado como não doente. E se nenhuma marcação fosse aparente, como $\mathrm{MH}$.
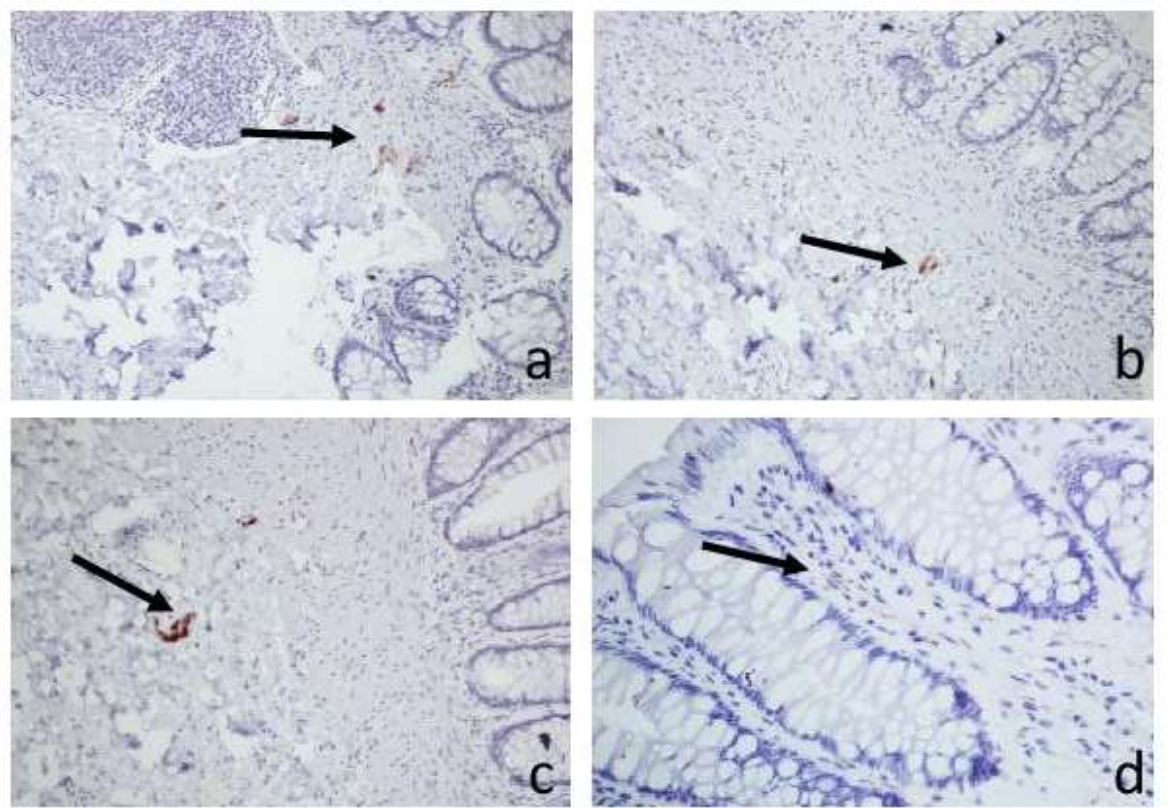

Figura 4 - Imagens de lâminas com marcação pela calretinina. Fotos a, b e c mostrando neurônios marcados com aumento de $20 x$. Foto d mostrando as fibrilas finas na lâmina própria, $40 x$.

O resultado final da avaliação de cada caso foi feito em consenso pelos pesquisadores.

\subsection{Análise Estatística}

Com a finalidade de analisar a concordância de resultados obtidos para o diagnóstico da MH usando os métodos de HE e Calretinina com aqueles obtidos pelo padrão ouro da $\mathrm{AChE}$, foram construídas tabelas de contingencia para a avaliação através de Kappa e o Qui-quadrado para os valores de sensibilidade e especificidade. 
Em todas as análises foi adotado um nível de significância de $5 \%$, tendo sido utilizado o software GraphPad Instat 3.0 para realizá-las. 
4. RESULTADOS 
Dos 50 casos estudados neste trabalho 24 eram de crianças que não apresentavam a doença e 26 de crianças com $\mathrm{MH}$, de acordo com diagnóstico realizado pelo padrão ouro da AChE.

\subsection{Comparação entre o método AChE com HE}

O método de coloração HE apresentou concordância com o método AChE, em $90 \%$ dos casos, com um índice Kappa de 0,800. Dos cinco casos discordantes, 2 foram de casos falso-positivos e 3 casos falso-negativos.
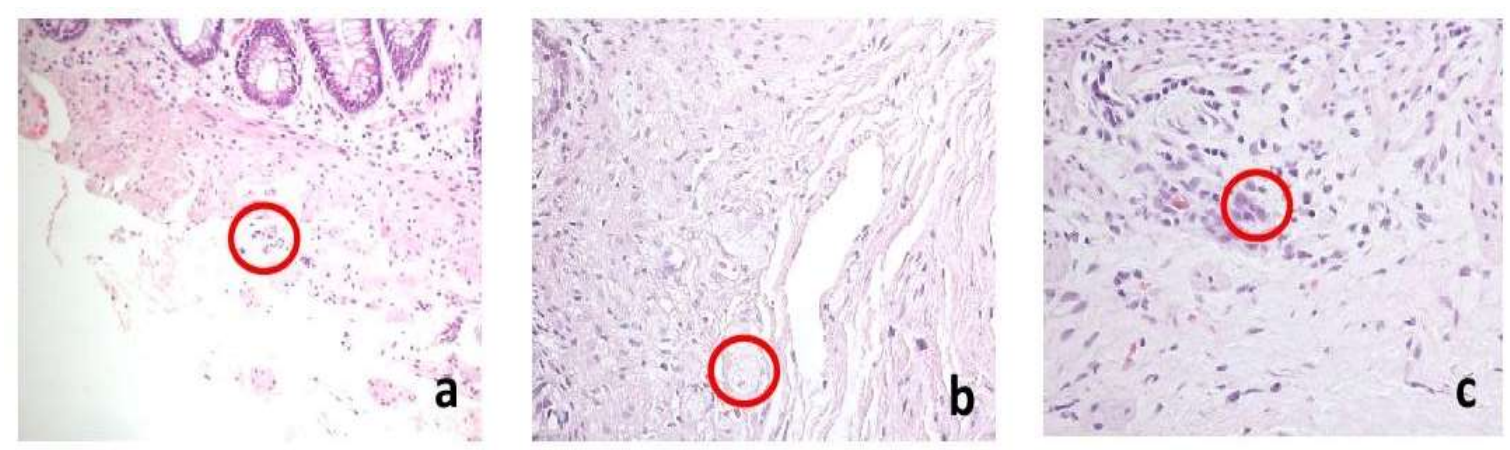

Figura 5 - Imagem dos casos de HE onde outras estruturas presentes foram interpretadas como neurônios. a aumento de 10x, b e c 20x. 
Tabela 1 - Comparação entre o diagnóstico realizado pela técnica do HE com os da AChE (padrão ouro). Negativo significa não doente e Positivo presença de $\mathrm{MH}$, para ambos os métodos.

\section{Comparação AchE x HE}

\begin{tabular}{|c|c|c|c|c|}
\hline & & \multicolumn{3}{|l|}{$\mathrm{HE}$} \\
\hline & & Negativo & Positivo & Total \\
\hline \multirow[t]{2}{*}{ AChE } & Negativo & 22 & 2 & 24 \\
\hline & Positivo & 3 & 23 & 26 \\
\hline Total & & 25 & 25 & 50 \\
\hline
\end{tabular}

AChE $\times$ HE

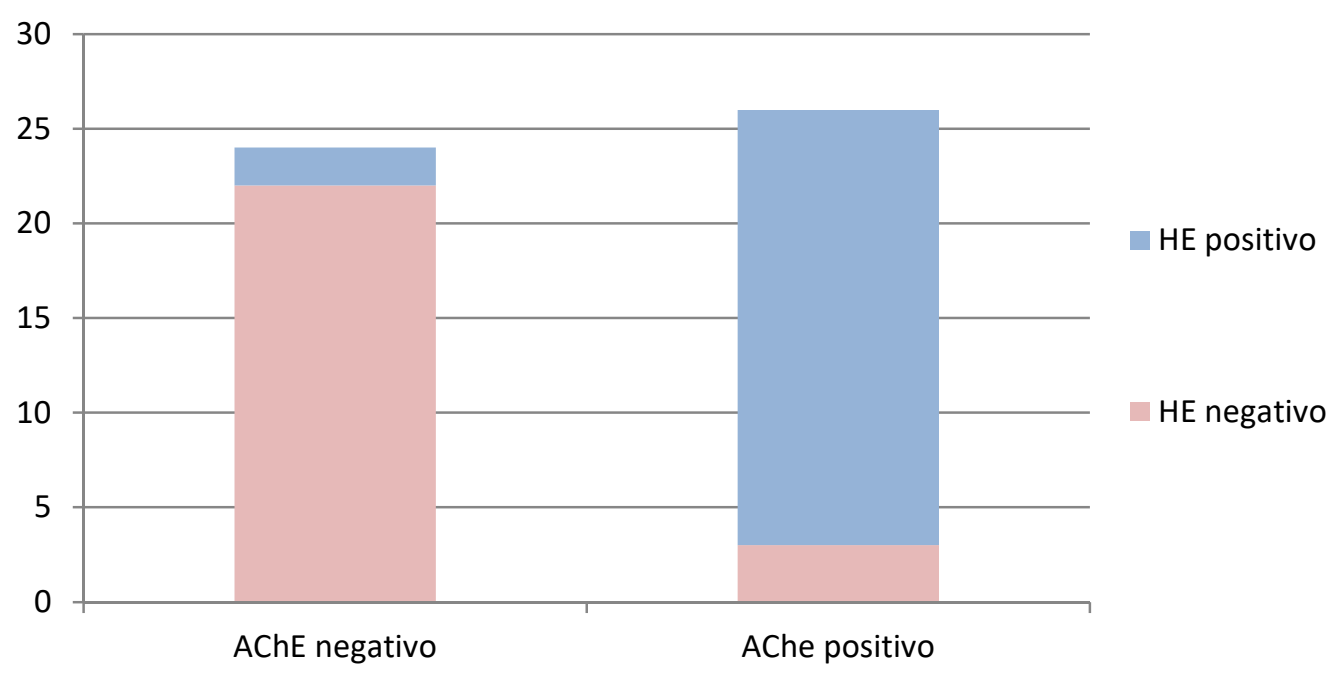

Gráfico 1 - Comparação entre o diagnóstico realizado pela técnica do HE com os da AChE (padrão ouro). Negativo significa não doente e Positivo presença de $\mathrm{MH}$, para ambos os métodos.

Além do Kappa de 0,800, que é considerado um bom índice de concordância, a técnica de HE também obteve altos valores de acurácia (90\%) e especificidade $(91,6 \%)$, como demonstrado na tabela 2 . 
Tabela 2 - Valores para validação do teste diagnóstico segundo a técnica da Hematoxilina \& eosina.

\begin{tabular}{l|l}
\multicolumn{2}{c}{ HE } \\
\hline Acurácia & 90,0 \\
Sensibilidade & 88,4 \\
Especificidade & 91,6 \\
Valor preditivo + & 92,0 \\
Valor preditivo - & 88,0
\end{tabular}

Durante a leitura das lâminas foi realizada a verificação aproximada dos níveis nos quais as células neuronais estavam presentes, ou seja, o primeiro corte histológico do bloco correspondia ao nível 1 , este foi cortado progressivamente até o nível 60 , o mais profundo. Em $54 \%$ dos 22 casos em que os neurônios foram visualizados, eles se encontravam nos níveis finais (50 - 60). Os outros $46 \%$ restantes, estavam distribuídos entre os 60 níveis.

\section{Incidência de células ganglionares}

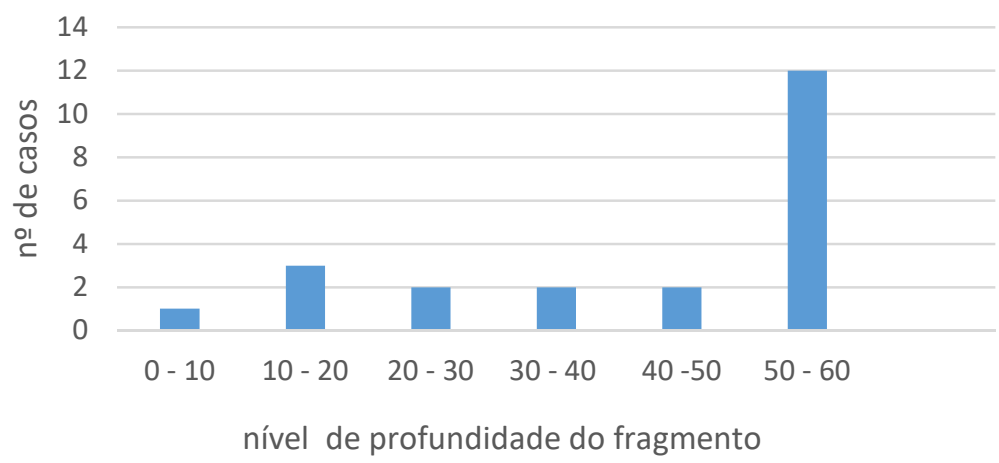

Gráfico 2 - Localização da célula neural durante a leitura das lâminas de HE. Nível aproximado.

\subsection{Comparação entre o método AChE com a Calretinina}

O método imunohistoquímico da calretinina apresentou uma concordância com o padrão ouro em $84 \%$ dos casos, com um valor de Kappa de 
0,676. Houve discordância em 8 casos. Entre estes, 7 casos foram positivos para $\mathrm{MH}$ e eram de pacientes não doentes e 1 caso de leitura negativa para $\mathrm{MH}$ e na verdade o paciente apresentava a doença.

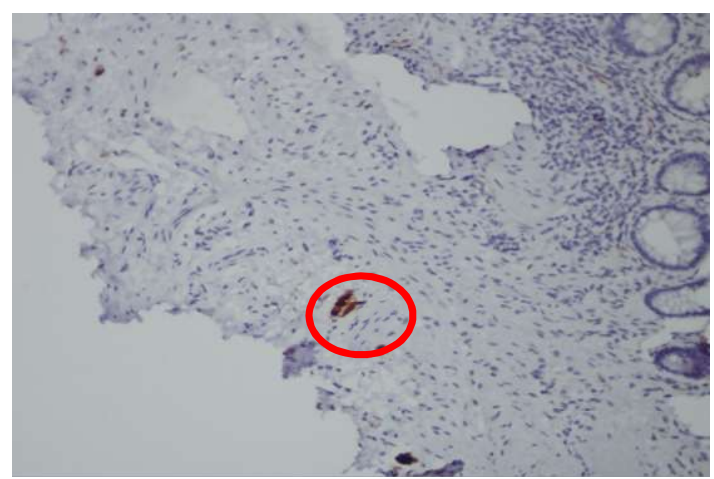

Figura 6 - Caso onde ocorreu uma marcação inespecífica na reação da calretinina, levando a um diagnóstico equivocado de não doente. Aumento de 20x.

Tabela 3 - Comparação entre o diagnóstico realizado pela técnica imunohistoquímica da Calretinina com os da AChE (padrão ouro). Negativo significa não doente e Positivo presença de $\mathrm{MH}$, para ambos os métodos.

\section{Comparação AchE x Calretinina}

\begin{tabular}{|c|c|c|c|c|}
\hline & & Calretinin & & \\
\hline & & Negativo & Positivo & Total \\
\hline \multirow[t]{2}{*}{ AChE } & Negativo & 17 & 7 & 24 \\
\hline & Positivo & 1 & 25 & 26 \\
\hline Total & & 18 & 32 & 50 \\
\hline
\end{tabular}




\section{AChE x Calretinina}

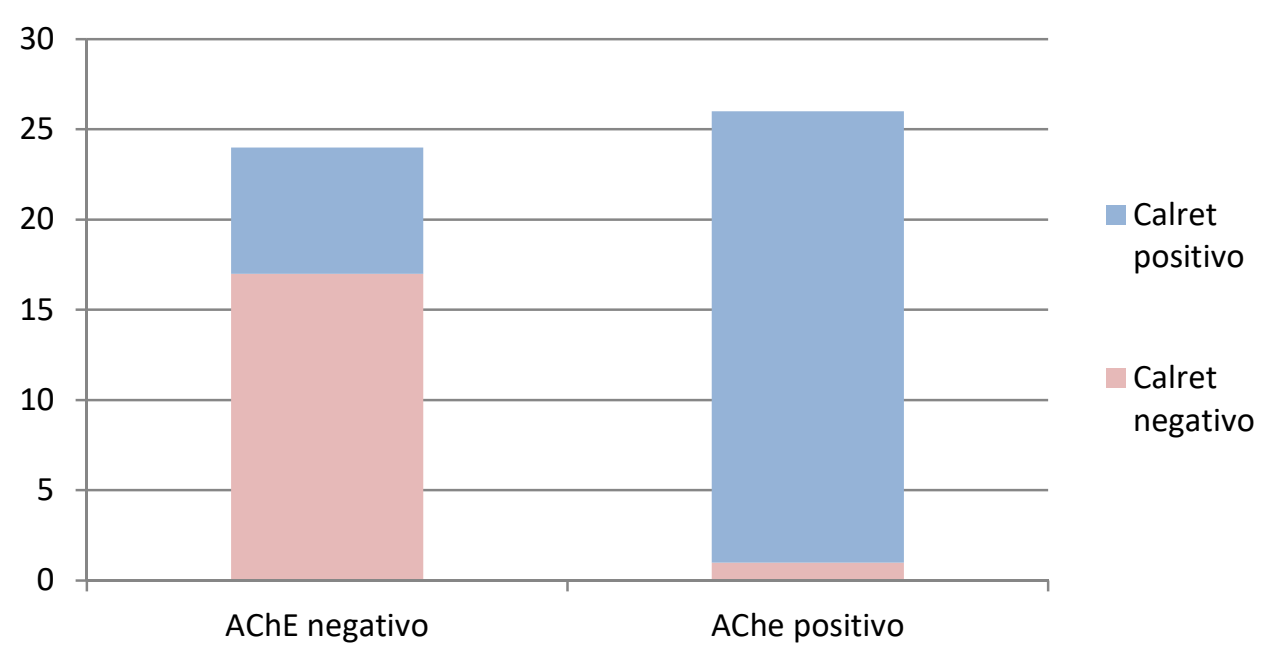

Gráfico 3 - Comparação entre o diagnóstico realizado pela técnica imunohistoquímica da Calretinina com os da AChE (padrão ouro). Negativo significa não doente e Positivo presença de $\mathrm{MH}$, para ambos os métodos.

A técnica da Calretinina obteve valores de acurácia e especificidade menores, $84 \%$ e $70 \%$.

Tabela 4 - Valores para validação do teste diagnóstico segundo a técnica imunohistoquímica da calretinina.

\begin{tabular}{l|l}
\multicolumn{2}{c}{ Calretinina } \\
\hline Acurácia & 84,0 \\
Sensibilidade & 96,0 \\
Especificidade & 70,0 \\
Valor preditivo + & 78,0 \\
Valor preditivo - & 94,0
\end{tabular}


5. DISCUSSÃO 
Embora a MH seja uma doença bastante estudada, ainda é considerada como um desafio no que diz respeito ao conhecimento da etiopatogenia e dos aspectos genéticos, entre outros, ainda não completamente elucidados ${ }^{3,7,8}$.

Desde que Whitehouse e Kernohan definiram as características fisiopatológicas da MH em 1948, a biópsia retal para a investigação da ausência de células neuronais tornou-se o método diagnóstico de certeza para a confirmação da doença. Apesar disso, existem muitas discussões acerca da melhor técnica para se tratar esse fragmento obtido por biópsia ${ }^{5}$.

Swenson em $1955^{36}$, demonstrou que com biópsia de fragmento de parede total de reto submetido à coloração por $\mathrm{HE}$, era possível diagnosticar a MH com uma acurácia aproximada de $98 \%$. Este tornou-se então o método clássico para a confirmação da doença. Porém, o procedimento para a obtenção deste fragmento de parede total do reto precisa ser realizado com anestesia geral, sendo, portanto, mais invasivo e com maior dificuldade para sua realização, sobretudo em pacientes recém-nascidos ${ }^{32,55}$.

Com o propósito de superar estas questões, Bodian (1960) sugeriu que o diagnóstico fosse realizado apenas em pequenos fragmentos de mucosa e submucosa corados por $\mathrm{HE}^{56}$. Mas este método gerou controvérsias porque, segundo outros pesquisadores, a distribuição difusa dos plexos submucosos 
dificultaria a visualização dos neurônios e aumentaria a chance de erro no diagnóstico $32,41,42$.

Então, após estudos de Meier-Ruge no ano de 1972, foi criada a técnica histoquímica da pesquisa de atividade de AChE, realizada em fragmentos de mucosa e submucosa congelados. Este método é considerado padrão-ouro em muitos serviços e, também, em nosso laboratório LIM30 - HCFMUSP que possui uma experiência de mais de 30 anos $^{6}$. Santos, M. M. (2008), através do estudo em 297 crianças com suspeita de $\mathrm{MH}$, demonstrou que a técnica da AChE possui uma acurácia de $93.5 \%$ no diagnóstico da doença ${ }^{41}$. Porém, devido à maior complexidade na sua execução, acrescido da necessidade de preparo rápido do material para evitar autólise, tornou o método pouco utilizado aqui no Brasil ${ }^{52,53}$.

Com o avanço das técnicas imunohistoquímicas foram surgindo marcadores para auxiliar no diagnóstico da $\mathrm{MH}$. O mais recente, a calretinina, tem apresentado bons resultados, com uma acurácia superior a 90\%. Mas, também apresenta uma complexidade maior na sua realização e um custo mais elevado $44,49,51$.

Neste trabalho, revisitamos a técnica clássica de coloração por HE em fragmentos de pequenas proporções, tal qual utilizado na pesquisa de AChE.

Existem controvérsias em relação à eficácia desta metodologia no diagnóstico da $\mathrm{MH}$. Swenson ${ }^{36}$ e Agrawal $^{42}$ usando a coloração $\mathrm{HE}$ em fragmentos de parede retal para o diagnóstico da $\mathrm{MH}$ observaram que a distribuição dos neurônios na região da submucosa se fazia de forma dispersa o que poderia dificultar o diagnóstico da doença, sobretudo quando só era feita a 
análise de um número pequeno de cortes de um mesmo fragmento. Esta foi a justificativa utilizada pelos autores para discordarem sobre o uso deste método no diagnóstico da $\mathrm{MH}$.

Kapur $^{2}$ et al, por sua vez, demonstraram que as limitações do método apontadas por Swenson ${ }^{36}$ e Agrawal ${ }^{42}$ poderiam ser superadas desde que mais cortes de um mesmo fragmento fossem analisados.

Entretanto, os trabalhos existentes sobre este tema mostram que ainda não há consenso a respeito do número ideal de cortes a serem analisados para uma melhor visualização dos plexos nervosos e consequentemente maior eficiência do método. Existem autores que citam a necessidade do estudo de 15 níveis e outros sugerem até 75 níveis por fragmento $2,9,31,52$.

Considerando a variação muito grande do número de secções sugeridas para serem analisadas, nos pareceu plausível adotarmos como metodologia para este trabalho, a análise de 60 secções por fragmento.

Após análise dos nossos resultados constatamos que nas crianças normais, os neurônios podem estar presentes em qualquer nível, havendo, entretanto, uma maior concentração de células neuronais (54\%) entre os níveis 50 a 60 do fragmento (gráfico 2).

Observamos também nos 50 casos estudados uma acurácia de $90 \%$ e um valor de Kappa de 0,800. Destes 50 casos, houve apenas 2 casos de pacientes não-doentes em que não foram visualizados neurônios na região da submucosa; e 3 casos de $\mathrm{MH}$ onde, durante a leitura das lâminas, alguma outra estrutura foi confundida com células neurais. 
A acurácia obtida neste estudo, aproxima-se daquelas obtidas por outros métodos utilizados no diagnóstico da $\mathrm{MH}$, como a coloração por HE em biópsia de parede retal e a pesquisa de atividade de acetilcolinesterase, ambas com acurácia superior a $90 \% 6,9,36,41$.

Após a análise das lâminas, para que houvesse uma melhor compreensão dos resultados obtidos, embora não fosse o objetivo primordial do nosso trabalho, resolvemos analisar os prontuários dos pacientes em que o diagnóstico por HE apresentou discordância com a AChE. Observamos que os três pacientes que haviam sido diagnosticados por nós como normais segundo o HE, foram operados no ICR - HCFMUSP. O produto de ressecção cirúrgica foi analisado pelo Departamento de Patologia Central do HC, não apresentando células neurais. Tal resultado coincidia com o diagnóstico dado pela AChE.

Já os dois pacientes que foram considerados como portadores de $\mathrm{MH}$ segundo a interpretação da coloração de HE, não foram operados, pois tiveram o diagnóstico pela AChE, como normal. Estas crianças foram acompanhadas clinicamente e receberam alta após seguimento ambulatorial.

Apesar destas discordâncias consideramos que o exame de biópsia de mucosa e submucosa com coloração por HE, quando analisado no mínimo 60 níveis, seja uma técnica aplicável, devendo, como em qualquer outro método diagnóstico, ser confrontado com a clínica.

A técnica imunohistoquímica da calretinina, obteve um valor Kappa de 0.676, que é considerado um bom índice de concordância. Entretanto, quando estudamos a acurácia e especificidade isoladamente observamos que a acurácia foi $84 \%$ e a especificidade de $70 \%$. Tais valores são menos significativos, quando 
comparados com os resultados da literatura onde o acerto foi maior que $90 \%$, tanto para acurácia, quanto para especificidade ${ }^{35,44,49,51}$.

A análise dos 50 casos submetidos à técnica da calretinina demonstrou que houve discordância em 8 casos. Deste total 7 casos não apresentaram nenhuma marcação imunohistoquímica, o que levou a uma interpretação equivocada de $\mathrm{MH}$. Em apenas um caso, houve uma marcação inespecífica, o que levou a um diagnóstico de não-doente, quando de fato o paciente apresentava a $\mathrm{MH}$.

Essa discordância provavelmente foi decorrente da metodologia de obtenção dos cortes na preparação das lâminas. Os cortes de fragmento utilizados para a calretinina foram cortes mais profundos do bloco, onde o material de biópsia já era bastante exíguo, sendo fator decisivo na marcação imunohistoquímica. Este viés metodológico no preparo das lâminas gerou uma limitação da amostragem, podendo ter influenciando o resultado deste estudo.

Apesar de não ter tido um bom valor assertivo ao diagnóstico destes pacientes, a realização da técnica serviu como experiência na nossa aprendizagem, contribuindo para o aperfeiçoamento técnico do nosso laboratório.

Podemos considerar também, a partir dos nossos resultados, que a biópsia retal de mucosa e submucosa tratada pela coloração por $\mathrm{HE}$ em um número de 60 níveis por fragmento pode ser considerada como um método alternativo no diagnóstico da $\mathrm{MH}$ em locais onde técnicas mais específicas não são disponíveis. 
6. CONCLUSÕES 
A) A concordância obtida entre os métodos da AChE e HE foi satisfatória. Tornando possível a utilização do método do HE em fragmentos de mucosa e submucosa como alternativa para o diagnóstico da $\mathrm{MH}$.

B) Em nosso estudo a técnica imunohistoquímica da Calretinina não apresentou a concordância esperada com a pesquisa de atividade de AChE. 
7. ANEXOS 
Tabela com os resultados de leitura das lâminas. Onde $0=$ não doente; $\mathbf{1}=\mathbf{M H}$.

\begin{tabular}{|c|c|c|c|}
\hline CASOS & $\mathrm{HE}$ & AChE & Calret \\
\hline 1 & 0 & 1 & 1 \\
\hline 2 & 1 & 1 & 0 \\
\hline 3 & 1 & 0 & 1 \\
\hline 4 & 0 & 0 & 0 \\
\hline 5 & 0 & 0 & 0 \\
\hline 6 & 0 & 0 & 0 \\
\hline 7 & 1 & 1 & 1 \\
\hline 8 & 1 & 1 & 1 \\
\hline 9 & 1 & 1 & 1 \\
\hline 10 & 1 & 1 & 1 \\
\hline 11 & 0 & 0 & 0 \\
\hline 12 & 1 & 1 & 1 \\
\hline 13 & 0 & 0 & 1 \\
\hline 14 & 1 & 1 & 1 \\
\hline 15 & 0 & 0 & 0 \\
\hline 16 & 0 & 0 & 1 \\
\hline 17 & 1 & 1 & 1 \\
\hline 18 & 0 & 0 & 0 \\
\hline 19 & 0 & 0 & 0 \\
\hline 20 & 0 & 0 & 0 \\
\hline 21 & 1 & 1 & 1 \\
\hline 22 & 1 & 1 & 1 \\
\hline 23 & 0 & 0 & 1 \\
\hline 24 & 1 & 1 & 1 \\
\hline 25 & 1 & 1 & 1 \\
\hline
\end{tabular}




\begin{tabular}{|c|c|c|c|}
\hline 26 & 1 & 1 & 1 \\
\hline 27 & 1 & 1 & 1 \\
\hline 28 & 1 & 1 & 1 \\
\hline 29 & 0 & 0 & 0 \\
\hline 30 & 0 & 0 & 0 \\
\hline 31 & 1 & 1 & 1 \\
\hline 32 & 0 & 0 & 1 \\
\hline 33 & 1 & 1 & 1 \\
\hline 34 & 0 & 0 & 0 \\
\hline 35 & 0 & 1 & 1 \\
\hline 36 & 0 & 0 & 0 \\
\hline 37 & 1 & 1 & 1 \\
\hline 38 & 1 & 1 & 1 \\
\hline 39 & 0 & 0 & 1 \\
\hline 40 & 0 & 0 & 0 \\
\hline 41 & 0 & 1 & 1 \\
\hline 42 & 1 & 1 & 1 \\
\hline 43 & 1 & 1 & 1 \\
\hline 44 & 1 & 1 & 1 \\
\hline 45 & 0 & 0 & 0 \\
\hline 46 & 1 & 0 & 1 \\
\hline 47 & 0 & 0 & 0 \\
\hline 48 & 1 & 1 & 1 \\
\hline 49 & 0 & 0 & 0 \\
\hline 50 & 0 & 0 & 0 \\
\hline
\end{tabular}


8. REFERÊNCIAS BIBLIOGRÁFICAS 
1. GUGELMIN, ES.; Torres, LFB. - The accuracy of acetylcholinesterase reaction in rectal suction biopsy in the diagnosis of Hirschsprung's disease. J Bras Patol Med Lab. 41: 431-6, 2005.

2. KAPUR, RP. Practical pathology and genetics of Hirschsprung's disease. Semin in Pediatr Surg. 18: 212-23, 2009.

3. CONSOLATO, S. Hirschsprung's disease: Historical notes and pathological diagnosis on the occasion of the $100^{\text {th }}$ anniversary of $\mathrm{Dr}$. Harald Hirschsprung's death. World J Clin Pediatr.4(4):120-5, 2015.

4. SANTOS JR, JCM., Megacólon - Parte I: Doença de Hirschsprung. Rev Bras Coloproct. 3:196-209, 2002.

5. Whitehouse, FR.; Kernohan, JW. - Myenteric plexus in congenital megacolon - Study of eleven cases. Arch Intern Med. 82: 75-111, 1948.

6. BRITO, IA. Atividade de acetilcolinesterase na moléstia de Hirschsprung: características etárias e estudo evolutivo. São Paulo, Tese (Doutorado) - Faculdade de Medicina, Universidade de São Paulo, 1985.

7. AMIEL, J.; LYONNET, S. Hirschsprung disease, associated syndromes, and genetics: a review. J Med Genet. 38:729-39, 2001.

8. Torfs, C. An epidemiological study of Hirschsprung's disease in a multiracial California population. Proceedings of the Third International 
Meeting: Hirschsprung's Disease and Related Neurocristopathies. Evian, France; 1998.

9. SZYLBER, T.; MARSZATEK, A. Diagnosis of Hirschsprung's disease with particular emphasis on histopathology. A systematic review of current literature. Prz Gastroenterol. 9(5):264-9, 2014

10. MORRIS, MI.; SOGLIO, DB.; OUIMET, A.; ASPIROT, A.; PATEY, N. A study of calretinin in Hirschsprung pathology, particularly in total colonic aganglionosis. J Pediatr Surg, 48:1037-43, 2013.

11. da SILVEIRA, AB.; LEMOS, EM.; ADAD, SJ.; CORREA-OLIVEIRA, R.; FURNES, JB.; D'AVILLA, DR. Megacolon in Chagas disease: a study of inflammatory cells, enteric nerves, and glial cells. Hum Pathol. 38:125664, 2007.

12. TSAI, HY.; MURAKAMY, N.; GARIEPY, CE. Postnatal intestinal engraftment of prospectively selected neural crest stem cells in a rat model of Hirshsprung disease. Neurogastroenterol Motil. 23:362-9; 2011.

13. OKAMOTO, E; UEDA, T. Embryogenesis of intramural ganglia of the gut and its relation to Hirschsprung's disease. J Pediatr Surg. 2:437-43, 1967

14. DRUCKENBROD, NR.; EPSTEIN, ML. Behavior of enteric neural crestderived cells varies with respect to the migratory wave front. Dev Dyn. 236:84-92, 2007. 
15. LAKE, JI.; HEUCKEROTH, RO. Enteric nervous system developmente: migration, differentiation, and disease. Am J Physiol Gastrointest Liver Physiol. 305:G1-G24, 2013.

16. GOLDENSTEIN, A.; HOFSTRA, R.; BURNS, AJ. Building a brain in the gut: development of the enteric nervous system. Clin Genet. 83:307-16, 2013.

17. FURNESS, JB. The enteric nervous system: normal fuctions and enteric neuropathies. Neurogastroenterol Motil. 20:32-8, 2008.

18. GOYAL, RK.; HIRANO, I. The enteric nervous system. N. Engl J Med. 334:1106-15, 1996.

19. COSTA, M.; BROOKES, SJ.; HENNIG, G. Anatomy and physiology of the enteric nervous system. Gut. 47:15-26, 2010.

20. FURLAN, MMDP. Ontogenia e filogenia do sistema nervosa entérico. Arq Ciênc Saúde Unipar. 4: 149-57, 2000.

21. POWLEY, TL. Vagal input to the enteric nervous system. Gut. 47:30-6, 2000.

22. OVAlLE, WK.; NAHIRNEY, PC. Netter - Bases da Histologia. Ed Elsevier - RJ, 2008. p. 128-9 e 471.

23. LI, Z.; CARON, MG.; BLAKELY, RD.; MARGOLIS, KG.; GERSHON, MD. Dependence of serotonergic and other noradrenergic enteric neurons on norepinephrine transporter expression. J Neurosci. 31:8998-9009, 2011. 
24. COELHO MC, TANNURI U.; BENDITT, I.; SANTOS, MM. Studies of RET gene expression and acetylcholinesterase activity in a series of sporadic Hirschsprung's disease. Pediatr Surg Int. 24:1017-21, 2008.

25. Kenny SE, Tam PKH, Garcia-Barcelo M. Hirschsprung's disease. Semin Pediatr Surg. 2010;19(3):194-200.

26. JIANG, Q.; HO, Y.; HAO, L.; BERRIOS, C.N.; CHAKRAVARTI, A. Copy number variants in candidate genes are genetic modifiers of Hirschsprung disease. Plos one. 6(6): 1-6, 2011.

27. SANTOS, M.M. Megacolo congênito. In: Tannuri, U. Doenças cirúrgicas da criança e do adolescente. SP: Manole, 2010. - Coleção Pediatria. Instituto da Criança HC-FMUSP. v.13. p.219-29.

28. SCHAPPI, MG.; STAIANO, A.; MILLA, PJ.; SMITH VV.; DIAS, JA.; HEUSCHKEL, R. et al. A practical Guide for the Diagnosis of primary enteric nervous system disorders. J Pediatr Gastroenterol Nutr. 57(5): 677-84, 2013.

29. TJADEN, N.; TRAINOR, P.A. The Developmental etiology and pathogenesis of Hirschsprung disease. Transl Res. 162(1):1-15, 2013.

30. SWAMINATHAN, M.; KAPUR, RP. Counting myenteric ganglions cells in histologic sections: an empirical approach. Hum Pathol. 41: 1097-108. 
31. QUALMAN, SJ.; JAFFE, R.; BOVE, KE.; MONFORTE-MUÑOZ, $H$. Diagnosis of Hirschsprung Disease using the rectal biopsy: Multiinstitucional Survey. Pediatr Dev Pathol. 2:588-96, 1999.

32. KOBAYASHI, H.; LI, Z.; YAMATAKA, A.; LANE, GJ.; MIYANO, T. Rectal biopsy: what is the optimal procedure? Pediatr Surg Int. 18:753-6, 2002.

33. KAPUR, RP.; KENNEDY, AJ. Trasitional zone pull through: surgical pathology considerations. Semin Pediatr Surg. 21:291-301, 2012.

34. KNOWLES, CH.; MARTIN, JE. Enteric Neuromuscular Pathology Update. Gastroenterol Clin North Am.40:695-713, 2011.

35. GONZALO, DH.; PLESES, T. Hirschsprung Disease and Use of Calretinin in Inadequate Rectal Suction Biopsies. Arch Pathol Lab Med. 137:1099$102,2013$.

36. SWENSON, O.; SHERMAN, J.O.; FISCHER, J.H. Diagnosis of congenital megacolon: an analysis of 501 patients. J Pediatr Sur. 8:587-93, 1973.

37. TOLOSA, EMC.; RODRIGUES, CJ.;BEHMER, OA.; FREITAS NETO, A. Manual de técnicas para histologia normal e patológica. Ed. Manole São Paulo, 2003. p. 80.

38. MONFORTE-MUÑOZ, H.; GONZALES-GOMEZ, I.; ROWLAND, JM.; LANDING, BH. Increased submucosal nerve trunk in aganglionosys, a "positive" and objective finding in suction biopsies and segmental 
resections in Hirschsprung's disease. Arch Pathol Lab Med. 122:721-5, 1998.

39. MEIER-RUGE, WA.; LUTTERBECK, P.M.; HERZOG, B.; MORGER, R.; MOSER, R.; SCHÄRLI, A. Acetylcholinesterase activity in suction biopsies of the rectum in the diagnosis of Hirschsprung's disease. J Pediatri Surg. 7:11-7, 1972.

40. MEIER-RUGE, WA.; BRUDER, E. Current concepts of enzyme histochemistry in modern pathology. Pathobiol. 75(4):233-43, 2008.

41. SANTOS, M.M.; TANNURI, U.; COELHO, MC. Study of acetylcholinesterase activity in rectal suction biopsy for diagnosis of intestinal dysganglionoses: 17-year experience of a single center. Pediatric Surg Int.24: 715-9, 2008.

42. AGRAWAL, R.K.; KAKKAR, N.; VASISHTA, R.K.; KUMARI, V. SAMUJH, R.; RAO, K.L.N. Acetylcholinesterase histochemistry (AChE) - A helpful technique in the diagnosis and in aiding the operative procedures of Hirschsprung disease. Diagnostic Pathology. 10: 1-8, 2015.

43. KARNOVSKY, M.J.; ROOTS, L. - A "direct-coloring" thiocholine method for cholinesterases. J Histochem Cytochem 12:219-21, 1964.

44. LOURENÇÃO, PL.; TAKEGAWA, BK.; ORTOLAN, EV.; TERRA, SA.; RODRIGUES, MA. A useful panel for diagnosis oh Hirshsprung disease in 
rectal biopsies: calretinin immunostaining and acetylcholinesterase histochemistry. An Diag Pathol. 17:352-6, 2013.

45. PARK, W.H.; CHOI, S.O.; KWON, K.Y.; CHANG, E.S. Acetylcolinesterase histochemistry of rectal suction biopsies in the diagnosis of Hirschsprung's disease. Journal of Korean Medical Science. 7(4): 353-9, 1992.

46. MUKHOPADHYAY, B.; MUKHOPADHYAY, M.; MONDAL, K.C.; SENGUPTA, M.; PAUL, A. Hirschsprung's disease in neonates with special reference to calretinin immunohistochemistry. J Clin Diag Res. 9(7): 6-9, 2015

47. GERAMIZADEH, B.; AKBARZADEH, E.; IZADI, B.; FOROUTAN, HR.; HEIDARI, T. Immunohistochemical study of enteric nervous system in hirschsprung's disease and intestinal neuronal dysplasia. Histol Pathol. 28:345-51, 2013.

48. AUBER, F.; DANZER, E.; NOCHÉ-MONNERY, ME.; SARNACKI, S.; TRUGNAN, G.; BOUDJEMAA, S.; AUDRY, G. Enteric Nervous System Impairmente in Gastroschisis. Eur J Pediatr Surg. 23:29-38, 2013.

49. BARSHACK, I.; FRIDMAN, E.; GOLDBERG, I.; CHOWERS, Y.; KOPOLOVIC, J. The loss of calretinin expression indicates aganglionosis in Hirschsprung's disease. J Clin Pathol. 57:712-6, 2004.

50. HOLLAND, SK.; HESSLER, RB.; REID-NICHOLSON, MD.; RAMALINGAM, P.; LEE, JR. Utilization of peripherin and S100 
immunohistochemistry in the diagnosis of Hirschsprung disease. Mod Pathol. 23:1173-9, 2010.

51. ALEXANDRESCU, S.; ROSENBERG, H.; TATEVIAN, N. Role of calretinin immunohistochemical stain in evaluation os Hirschsprung disease:an istutional experience. Int J Clin Exp Pathol. 6(12):2955-61, 2013.

52. ANDRASSY, R.J.; ISAACS, H.; WEITZMAN, JJ. Rectal suction biopsy for the diagnosis of Hirschsprung's disease. Ann Surg 193:419-24, 1981.

53. ATHOW, A.C.; FILIPE, MI.; DRAKE, DP. Problems and advantages of acetylcholinesterase histochemistry of rectal suction biopsies in the diagnosis of Hirschsprung's disease. J Pediatr Surg. 25:520-6, 1990.

54. HANKER, J.S.; THOMBURG, L.P.; YATES, P.E.; MOORE, H.G. The demonstration of cholinesterases by the formation of osmium blacks at the sites of Hatchett's brown. Histochemie.37:223-42, 1973.

55. BRADY, A.; SAITO J.; LUKAS, K.; GUTHRIE, T.; UTTERSON, EC.; WHITE, FV.; DILLON, PA. Suction rectal biopsy yields adequate tissue in children. J Pediatr Surg. 51:966-9, 2016.

56. Bodian M. Pathological aids in the diagnosis and management of Hirschsprung's disease. In:Dyke, SC, editor. Recent Advances in Clinical Pathology. Series 3. London: Churchill; 1960.p. 384. 